\title{
Inhibition of cell mediated cytotoxicity by sulphasalazine: effect of in vivo treatment with 5 -aminosalicylic acid and sulphasalazine on in vitro natural killer cell activity
}

\author{
M N Aparicio-Pagés, H W Verspaget, J C M Hafkenscheid, G E Crama-Bohbouth, A S Peña, \\ I T Weterman, C B H W Lamers
}

\begin{abstract}
Decreased cell mediated cytotoxicity occurs frequently in inflammatory bowel disease, particularly in patients with active disease. It is not clear, however, whether this decrease is caused by the disease or is a consequence of the medical treatment. In this study we evaluated the effect of in vivo treatment with 5 -aminosalicylic acid and sulphasalazine on the in vitro natural killer cell activity in five patients with inflammatory bowel disease in remission and in four healthy control subjects in a double blind randomised crossover trial preceded and separated by four weeks of treatment with placebo. The natural killer cell activity was significantly impaired in $67 \%$ (six of nine subjects) after four weeks' sulphasalazine treatment and tended to be related to subjects with a slow acetylator phenotype. In contrast, 5-aminosalicylic acid treatment caused only a marginal reaction in the natural killer cell activity in $22 \%$ (two of nine subjects). The inhibitory effects were found to be reversible since the decreased natural killer cell activity was completely restored after placebo treatment in all subjects. In conclusion, in vivo treatment with sulphasalazine inhibits the in vitro natural killer cell activity and this seems to be mediated by the sulphapyridine moiety. This phenomenon may contribute to the low natural killer cell activity found in patients with active inflammatory bowel disease.
\end{abstract}

Department of

Gastroenterology and

Hepatology, University

Hospital Leiden, The

Netherlands

M N Aparicio-Pagés

$\mathrm{HW}$ Verspaget

G E Crama-Bohbouth

A S Peña

I T Weterman

C B H W Lamers

Department of Clinical Chemistry, University Hospital Nijmegen, The Netherlands J C M Hafkenscheid

Correspondence to: Dr HW Verspaget, Department of Gastroenterology and Hepatology, University Hospital, Building 1, C4-P012, Rijnsburgerweg 10, 2333 AA Leiden, The Netherlands

Accepted for publication 20 November 1989
Natural killer cells have a role in many aspects of the inmmunological defence system. Their major function is induction of cytolysis of malignant and virus infected cells. ${ }^{1}$ Besides their involvement in cellular immune mechanisms, they also play a part in the humoral immune response, as shown by the interaction with $B$ cells in the regulation of the immunoglobulin synthesis. ${ }^{2}$ With regard to cellular cytotoxicity, several studies have shown that natural killer cell activity is impaired in patients with inflammatory bowel disease. ${ }^{3-6}$ Moreover, in some studies this impairment was found to be related to the disease activity. ${ }^{78}$ The major problem with the interpretation of results obtained in patients with active disease, however, is that it is usually impossible to determine whether disease activity or the effect of medical treatment is the cause of impaired natural killer cell activity.

Sulphasalazine is a commonly used drug for the treatment of inflammatory bowel disease and rheumatoid arthritis. Its mode of action is still unclear, although it has been shown to possess both antibacterial and immunosuppressive activity. The active moiety seems to be 5aminosalicylic acid in inflammatory bowel disease and sulphapyridine in rheumatoid arthritis. ${ }^{\text {-11 }}$ The immunosuppressive activity of the drugs has been illustrated by inhibition of phagocyte chemotaxis, oxygen metabolite production, leukotriene production, and lymphocyte proliferative activity in vitro. ${ }^{12-15}$ Moreover, sulphasalazine and sulphapyridine were recently shown to inhibit in vitro cellular cytotoxicity of both peripheral blood and intestinal mononuclear cells. ${ }^{16-18}$ It is still unclear, whether in vivo treatment with sulphasalazine has a similar inhibitory effect on natural killer cell activity. Since deranged cell mediated cytotoxicity does not seem to be involved in the pathogenesis of inflammatory bowel disease, ${ }^{56}$ inhibition of natural killer cell activity by sulphasalazine may result in insufficient clearing of infected and malignant cells.

In this study we evaluated the effect of 5aminosalicylic acid and sulphasalazine treatment on the in vitro activity of peripheral blood natural killer cells in five patients with inflammatory bowel disease in remission and in four healthy control subjects.

\section{Material and methods}

\section{STUDY DESIGN}

We studied five patients with inflammatory bowel disease (one with Crohn's disease and four with ulcerative colitis) in remission and four healthy volunteers in a double blind randomised crossover trial. Both drugs were administered orally, 5-aminosalicylic acid at a dose of $500 \mathrm{mg}$ four times a day and sulphasalazine at a dose of $1000 \mathrm{mg}$ four times a day for four week periods preceded and separated by four week placebo treatment periods (double dummy design). The

TABLE I Natural killer cell activity of patients and control subjects after four weeks' treatment with 5-aminosalicylic acid (5-ASA), placebo, and sulphasalazine (SASP)

\begin{tabular}{llll}
\hline & $5-A S A$ & Placebo $^{\star}$ & SASP \\
\hline Controls $(\mathrm{n}=4)$ & $62 \cdot 5(6 \cdot 3) \dagger$ & $59 \cdot 2(5 \cdot 9)$ & $26 \cdot 2(18 \cdot 3)$ \\
Patients $(\mathrm{n}=5)$ & $52 \cdot 5(9 \cdot 1)$ & $74 \cdot 4(4 \cdot 8)$ & $40 \cdot 2(18 \cdot 2)$ \\
All $(\mathrm{n}=9)$ & $56 \cdot 9(5 \cdot 7)$ & $67 \cdot 6(4 \cdot 4)$ & $34 \cdot 1(12 \cdot 4) \ddagger$ \\
\hline
\end{tabular}

* Mean percentage cytotoxicity of the two placebo periods. †Mean (SEM) percentage cytotoxicity.

$\dagger$ Mean $(S E M)$ percentage cytotoxicity.
$\ddagger p<0.05$ significance of differences compared with the placebo. 
drugs and matching placebo's were supplied by Tramedico-Falk (The Netherlands). At the end of each four week period blood was taken and the disease activity was determined by the Harvey and Bradshaw index ${ }^{19}$ from diary cards maintained by the patients during the whole period. The four healthy volunteers had no physical disorders and were taking no medication.

\section{CYTOTOXICITY ASSAY}

Mononuclear effector cells were obtained by Ficoll-Hypaque density gradient centrifugation of heparinised peripheral blood. The cells were washed and resuspended in Roswell Park Memorial Institute 1640 culture medium supplemented with $10 \%$ heat inactivated fetal calf serum, $2 \mathrm{mM}$ glutamine, and antibiotics and after counting were brought to a concentration of $2.5 \times 10^{6}$ cells $/ \mathrm{ml}$. The viability of the cells always exceeded $97 \%$. The target cells used in the cytotoxicity assay were the K-562 erythroleukemia cell line cultured in the same culture medium. The K-562 cells were labelled with 100 $\mu \mathrm{Ci} / 5 \times 10^{6}$ cells of sodium ${ }^{51}$-chromate and used in a concentration of $1 \times 10^{5}$ cells $/ \mathrm{ml}$. The cytotoxicity assay was performed in triplicate at a 50:1 effector-target ratio in a volume of $200 \mu \mathrm{l}$. After 18 hours incubation, the supernatants of the 96 microwell plates were harvested (Skatron supernatant harvesting system). The released label was counted in a gamma counter. Spontaneous release was determined by incubation of the targets alone and maximal release by incubation of the target cells with saponin. Cytotoxicity was determined by the following formula:

$$
\text { Cytotoxicity }(\%)=\frac{\text { experimental release }- \text { spontaneous release }}{\text { maximal release }- \text { spontaneous release }} \times 100
$$

The reproducibility of this assay was good as illustrated by the intra-assay coefficient of variance $(2 \cdot 8 \% \pm 0 \cdot 5 \%)$ and the inter-assay coefficient of variance $(4 \cdot 2 \% \pm 1 \cdot 4 \%)$ determined by triplicate determinations of five subjects at two different time points.

Serum samples obtained at the end of each period were analysed for sulphasalazine, sulphapyridine, and acetyl-sulphapyridine by a colori-

sulphasalazine $(a)$ or 5 aminosalicylic acid (5-ASA)

(b) compared with the

preceding placebo period.
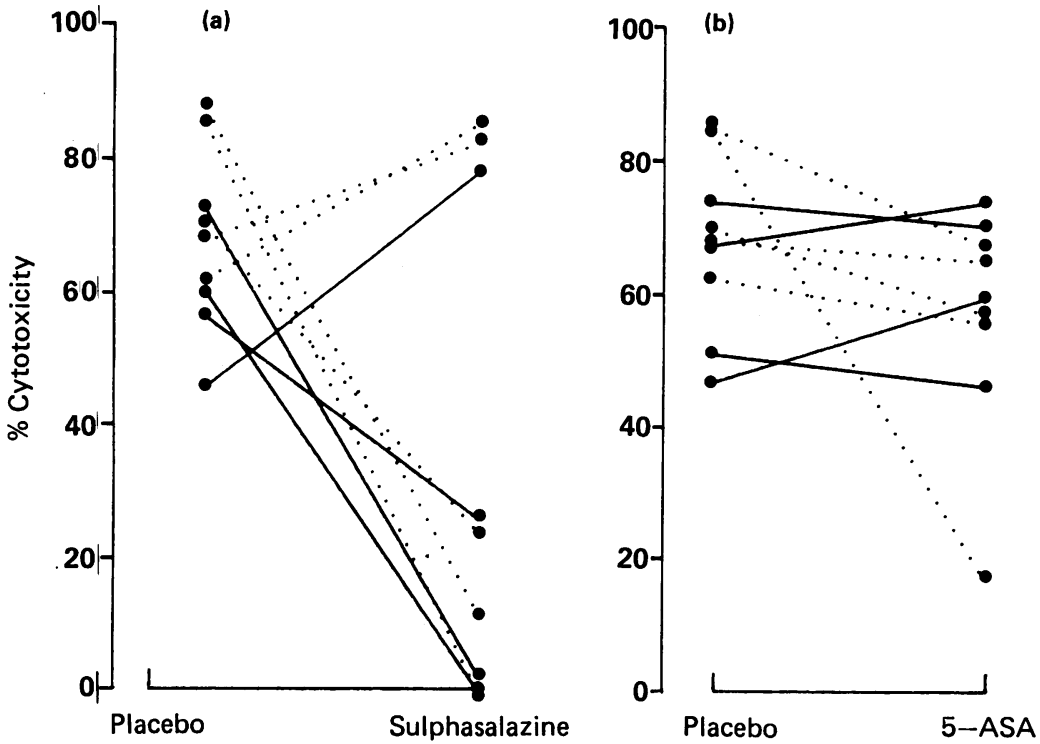

metric assay after hydrolysation and extraction of the serum as previously reported. ${ }^{20}$ The acetylator phenotype of each subject was determined by the percentage acetyl-sulphapyridine $v$ sulphapyridine+acetyl-sulphapyridine in the serum. When less than $30 \%$ of sulphapyridine was acetylated the subject was considered to have a slow acetylator phenotype. ${ }^{21}$

\section{STATISTICAL ANALYSIS}

All results are expressed as mean (SEM). Statistical significances of the differences were evaluated by the Student's $t$ test or the separate variance analysis when the standard deviations were statistically different.

\section{Results}

The natural killer cell activity was similar in patients and control subjects at the end of the placebo periods (Table I). The mean cytotoxicity values of the two placebo periods were identical in patients and controls (combined 64.6 (5) $v$ $68 \cdot 5(5 \cdot 7)$ ). Moreover, the reproducibility of the natural killer cell activity determinations, expressed as the correlation coefficient of the two placebo periods from patients and controls, was $\operatorname{good}(r=0.95, p<0.02)$.

The natural killer cell activity after the sulphasalazine period was significantly decreased both in patients and controls compared with the mean of the two preceding placebo periods $(p<0.05$, Table I). In contrast, 5 -aminosalicylic acid did not affect the natural killer cell activity in the control subjects and only marginally in the patients. The natural killer cell activity was impaired - that is, below the lowest placebo value $(46 \cdot 2 \%)$ - after sulphasalazine treatment in six $(67 \%)$ subjects (three patients and three controls) (Fig (a)), but was reduced in only two subjects (one patient and one control) after 5-aminosalicylic acid treatment (Fig (b)). All patients remained in remission during the different treatment periods. Thus, the changes in the natural killer cell activity were not attributable to the disease activity according to the Harvey and Bradshaw index (Table II). Neither the concentration of sulphasalazine nor of its metabolites in serum were found to be related to the change in natural killer cell activity or the resulting natural killer cell activity at the end of the sulphasalazine treatment period (Table III). The percentage of subjects with an impaired natural killer cell activity after sulphasalazine treatment tended to be higher, however, in the slow acetylator group $(80 \%$, four of five) than in the fast acetylator group ( $50 \%$, two of four).

\section{Discussion}

Treatment with sulphasalazine suppresses natural killer cell activity of peripheral blood cells in vitro, which seems to be more prominent in subjects with a slow acetylator phenotype. In contrast, 5-aminosalicylic acid had no significant effect on natural killer cell activity.

Studies on natural killer cells in inflammatory bowel disease indicate that these cells probably do not play a role in the pathogenesis of the 
TABLE II Disease activity of patients with inflammatory bowel disease according to the Harvey and Bradshaw index during the different periods of treatment.

\begin{tabular}{lllll}
\hline Patient & Placebo & $5-A S A$ & Placebo & SASP \\
\hline 1 & 2 & 0 & 0 & 0 \\
2 & 2 & 2 & 5 & 0 \\
3 & 0 & 0 & 2 & 0 \\
4 & 1 & 1 & 0 & 2 \\
5 & 0 & 0 & 0 & 1 \\
\hline
\end{tabular}

5-ASA = 5-aminosalicylic acid; $\mathrm{SASP}=$ sulphasalazine

disease. ${ }^{56}$ Peripheral blood natural killer cell activity is usually low in inflammatory bowel disease ${ }^{3-8}$ and the activity and number of natural killer cells in the intestinal wall are often so low that they are unlikely to lyse and destroy normal autologous epithelial cells. ${ }^{45}$ Natural killer cells do, however, take part in the immunological homeosteasis, and inhibition of their activity may have detrimental effects on the immunological defence mechanisms against infection and malignant disease. Previous studies on the effect of sulphasalazine and 5-aminosalicylic acid on natural killer cell activity were performed by addition of these drugs in vitro to the assay system. ${ }^{16-18}$ These studies showed unequivocally the inhibition of natural killer cell activity by sulphasalazine and sulphapyridine but not by 5 -aminosalicylic acid. In this study we showed that in vivo administration of sulphasalazine to patients with inflammatory bowel disease or controls also resulted in decreased natural killer cell activity. This effect was reversible, as shown after four weeks of treatment with placebo. Since this inhibitory effect is hardly observed with 5 -aminosalicylic acid, it is probable that the sulphapyridine moiety of sulphasalazine is mainly responsible for the inhibition of natural killer cells in vivo, which may also explain the higher frequency of inhibition in the slow acetylator subjects. Interestingly, sulphapyridine was also found to be the active component in the inhibition of the production of oxygen metabolites by granulocytes, indicating that this moiety seems to possess the most prominent immunosuppressive feature. ${ }^{13}$ The fact that sulphasalazine, and to a much lesser extent 5-aminosalicylic acid possesses natural killer cell inhibitory effects does not exclude disease activity as another cause of impaired natural killer cell activity in inflammatory bowel disease. We found no relation between prednisolone treatment and decreased natural killer cell activity in a previous study of patients with

TABLE III Serum concentrations of sulphasalazine (SASP) and its metabolites and natural killer (NK) cell activity after four weeks' treatment with SASP

\begin{tabular}{|c|c|c|c|c|c|c|}
\hline & $S A S P \star$ & $A c-S P \star$ & $S P \star$ & $\begin{array}{l}\% \text { Ac-SPt } \\
\text { (phenotype) }\end{array}$ & $N K$ before $\neq$ & NK after $\neq$ \\
\hline Patient 1 & 11 & 22 & 77 & 22 (slow) & $68 \cdot 1$ & $82 \cdot 4$ \\
\hline Patient 2 & 72 & 26 & 46 & 36 (fast) & $62 \cdot 4$ & $85 \cdot 3$ \\
\hline Patient 3 & 10 & 44 & 50 & 47 (fast) & $87 \cdot 7$ & $11 \cdot 1$ \\
\hline Patient 4 & 18 & 57 & 279 & 17 (slow) & $69 \cdot 9$ & $23 \cdot 4$ \\
\hline Patient 5 & 3 & 23 & 100 & 19 (slow) & $85 \cdot 4$ & $-1 \cdot 0$ \\
\hline Control 1 & 2 & 48 & 23 & 68 (fast) & $45 \cdot 7$ & $78 \cdot 1$ \\
\hline Control 2 & 0 & 37 & 13 & 74 (fast) & $56 \cdot 3$ & $25 \cdot 6$ \\
\hline Control 3 & 4 & 6 & 58 & 9 (slow) & 59.9 & -0.6 \\
\hline Control 4 & 0 & 6 & 20 & 23 (slow) & $72 \cdot 3$ & 1.8 \\
\hline
\end{tabular}

*SASP, acetyl-sulphapyridine (Ac-SP), and sulphapyridine (SP) in $\mu \mathrm{mol} / \mathrm{l}$.

tDetermined by Ac-SP/(Ac-SP+SP), between parentheses acetylator phenotype. †\% Cytotoxicity. inflammatory bowel disease ${ }^{8}$ and MacDermott $e t$ $a l^{4}$ found low natural killer cell activity in untreated active inflammatory bowel disease.

In conclusion, treatment with sulphasalazine, in contrast to treatment with 5-aminosalicylic acid, can inhibit natural killer cell activity in vitro. This treatment may contribute to impaired natural killer cell activity in some patients. The decreased natural killer cell activity in patients with inflammatory bowel disease, however, is one of the many immunological changes that occur during the inflammatory process and are probably secondary to the disease.

We thank M A C Mieremet-Ooms, J M van der Zon, and B E M Kohler for their technical assistance; L Niepoth and M Koster-de Vreese for typing the manuscript; and I J Kuijpers for the figure design.

The financial support of Tramedico BV, The Netherlands, and the Falk Foundation, West-Germany, is gratefully acknowledged.

1 Herberman RB. Possible role of natural killer cells in host resistance against tumours and other diseases. Clin Immuno Allergy 1983; 3: 479-94.

2 Mason PD, Weetman AP, Sissons JGP, Borysiewicz LK. Suppressive role of NK cells in pokeweed mitogen-induced immunoglobulin synthesis: effect of depletion/enrichmen of the Leu $11 \mathrm{~b}^{+}$cells. Immunology 1988; 65: 113-8.

3 Ginsburg CH, Dambrauskas JT, Ault KA, Falchuck Z. Impaired natural killer cell activity in patients with inflammatory bowel disease: evidence for a qualitative defect. Gastroenterology 1983; 85: 846-51.

4 MacDermott RP, Bragdon MJ, Kodner IJ, Bertovich MJ Deficient cell-mediated cytotoxicity and hyporesponsiveness to interferon and mitogenic lectin activation by inflammatory bowel disease peripheral blood and intestinal mononuclear cells. Gastroenterology 1986; 90: 6-11.

5 Gibson PR, Jewell DP. Local immune mechanisms in inflammatory bowel disease and colorectal carcinoma: natural
killer cells and their activity. Gastroenterology 1986;90: 12-9.

6 Aparicio-Pagés MN, Verspaget HW, Peña AS, et al. Natural, lectin- and phorbol ester-induced cellular cytotoxicity in Crohn's disease and ulcerative colitis. F Clin Lab Immunol 1988; 27: 109-13.

7 Auer IO, Ziemer E, Sommer H. Immune status in Crohn's disease. V. Decreased in vitro natural killer cell activity in peripheral blood. Clin Exp Immunol 1980; 42: 41-9.

8 Aparicio-Pagés MN, Verspaget HW, Peña AS, et al. In vitro cellular cytotoxicity in Crohn's and ulcerative colitis: relation with disease activity and treatment, and the effect of recombinant gamma-interferon. F Clin Lab Immunol 1989 29: 119-24.

9 Bachrach WH. Sulfasalazine: I. An historical perspective. Am F Gastroenterol 1988; 83: 487-96.

10 Svartz N. Sulfasalazine: II. Some notes on the discovery and development of salazopyrin. Am F Gastroenterol 1988; 83: 497-503.

11 Taggart AJ, Neumann VC, Hill J, Astbury C, Le Gallez P, Dixon JS. 5-Aminosalicylic acid or sulphapyridine. Which is the active moiety of sulphasalazine in rheumatoid arthritis? the active moiety of sulphasalazine

12 Nielsen OH, Verspaget HW, Elmgreen J Inhibition of intestinal macrophage chemotaxis to leukotriene $B_{4}$ by sulphasalazine, olsalazine, and 5-aminosalicylic acid Aliment Pharmacol Therap 1988; 2: 203-11.

13 Miyachi Y, Yoshioka A, Imamura S, Niwa Y. Effect of sulphasalazine and its metabolites on the generation of reactive oxygen species. Gut 1987; 28 : 190-5.

14 Sharon P, Stenson WF. Enhanced synthesis of leukotriene B by colonic mucosa in inflammatory bowel disease. Gastroenterology 1984; 86: 453-60.

15 Holdstock G, Chastenay BF, Krawitt EL. Increased suppressor cell activity in inflammatory bowel disease. Gut 1981; 22: 1025-30.

16 MacDermott RP, Kane MG, Steele LL, Stenson WF. Inhibition of cytotoxicity by sulfasalazine. I. Sulfasalazine inhibits spontaneous cell-mediated cytotoxicity by peripheral blood and intestinal mononuclear cells from controls and inflammatory bowel disease patients. Immunopharmacology 1986 11: 101-9.

17 Shanahan F, Niederlehner A, MacDermott RP, Stenson WF, Kane MG, Targan S. Inhibition of cytotoxicity by sulfasalazine. II. Sulfasalazine and sulfapyridine inhibit differen stages of the NK and NKCF lytic processes. Immunopharmacology 1986; 11: 110-8.

18 Gibson PR, Jewell DP. Sulphasalazine and derivatives, natura killer cell activity and ulcerative colitis. Clin Sci 1985; 69: 177-84

19 Harvey RF, Bradshaw JM. A simple index of Crohn's disease activity. Lancet 1980; i: 514.

20 Hansson KA, Sandberg M. Determination of sulphapyridine and its metabolites in biological materials after administration of salicylazosulphapyridine. Acta Pharm Suec 1973; 10: 87-92.

21 van Hees PAM. Clinical and pharmacological aspects of sulphasalazine [Thesis]. Pharmacokinetics and metabolism of sulphasalazine. University of Nijmegen, The Netherlands 1979: 57-92. 